\title{
Design on Software Function and Safety Control for Accounting Computerization
}

\author{
Tiesong Qiao \\ College of Finance and Trade, Bohai University, Jinzhou, 121013, China \\ 273138500@qq.com
}

Keywords: accounting computerization; software function; safety control; design

\begin{abstract}
Accounting computerization to improve the efficiency and quality of accounting work, promote the accounting work standardization, has paved the way for the modernization and information of accounting management. In this paper out research the development of accounting computerization systems difficult problem. First of all, the design by the "Budget management module, Contract management module, Rights management module, Inventory accounting module, Salary management module, the Accounts payable module, the Accounts receivable module, accounting processing module, Report management module, Fixed assets module, Cost management module and Financial analysis module" is composed of software function; Then, design the schedule by the Security control center "Security assurance platform and Security monitoring platform" common Security control mechanism. The research achievements of this paper can solve the problem of key software development technology, improve the quality of the accounting computerization software plays an important role and promote the accounting computerization software applications.
\end{abstract}

\section{Introduction}

Accounting computerization is the electronic computer main of modern electronic technology and information technology application in accounting practice, and it is an application of the electronic computer accounting information system implementation. Realize the automation of data processing, the traditional manual accounting information system development of computerized accounting information system. Accounting computerization is accounting in the history of the development of a major revolution, is not only the needs of the development of accounting, and economic and technological demands for accounting work.

Enterprises and institutions in application of accounting computerization system is of great significance: reduce the labor intensity of financial personnel, improve the efficiency of the accounting, the broad financial personnel from multifarious freed, accounts and reimbursement charge to an account; Promote the accounting work standardization, improve the quality of accounting work, solve the manual operation is not standard, prone to errors and omissions, etc. Promote improve the quality of financial personnel, on the one hand, a lot of work done by the computer, the accounting personnel have more time to learn the new knowledge of accounting and management. On the other hand, the knowledge structure of the financial personnel to update, quality enhances unceasingly; Promote the change of accounting work function, make the accounting personnel have a lot of time to complete analysis, prediction and decision of accounting information; Promote the development of accounting theory and accounting practice, and promote the reform of accounting system; Accounting information is an important part of enterprise management information, realize the accounting computerization has paved the way for the enterprise management modernization.

Software function is a software should have the efficiency and effect, software goal through software functions to express and implementation, software function and software is presented to the user directly effect. Security control means for computerized accounting system and its information transmission provides safety control safeguard mechanism, make the system state, whether in storage, processing or transmission in are ensured by corresponding safety control, to 
ensure that the information in the system control and safety. Software function and safety control design is always the difficult problem of the accounting computerization software design, the researches on the two problems, the author of this paper, for the development and implementation of computerized accounting system to provide technical solution.

\section{Software Function Design}

Said software functions of general function structure of the system that function chart is said after the system functional decomposition according to the functional dependency of graphics, each a rectangular box in this picture is called a function module, the upper module to control the lower module, the more the upper module function, the general, the lower level module function, the concrete. Functional decomposition process is a from abstract to concrete, from complex to simple process, function modules can be resolved according to the specific situation to larger or smaller. Computerized accounting system is based on accounting treatment function as the core, including the organic combination of a variety of functions. System according to the function is divided into several relatively independent subsystems, each subsystem of the accounting information transmission and exchange each other, forming a complete accounting system. Software function structure design as shown in Fig. 1.

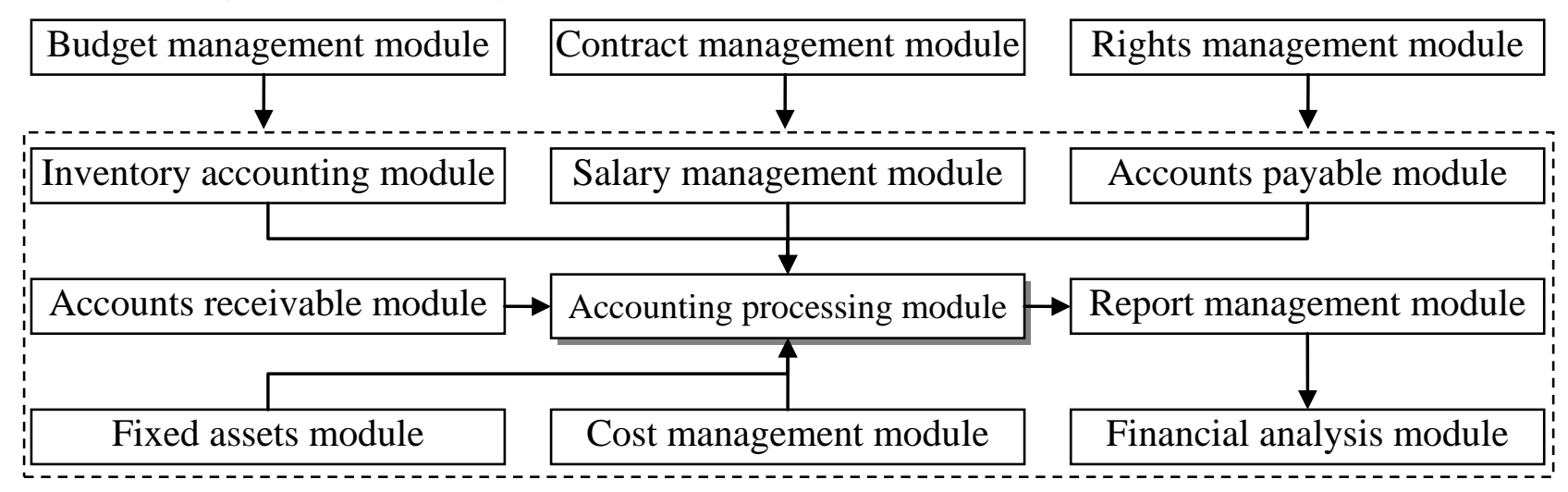

Fig. 1. Software function structure on accounting computerization

The functional description of shown in figure 1 below [1-4]:

(1) The Budget management module. Budget is the quantitative behavior plan, help managers to coordinate and implement the plan. Enterprises under the guidance of the strategic target, the future business activities and corresponding financial results are sufficient and comprehensive prediction and planning, monitoring and through the implementation process, the actual completion and budget targets constantly contrast and analysis, to guide the business activities to improve and adjust in time, to help managers more effectively management enterprise and to achieve strategic goals.

(2) The Contract management module. Contract management is an important content of enterprise management, through strengthening management, standardize enterprise contract signing and implementation of effective risk prevention, optimal management, reduce costs and improve efficiency. Contract, contract management module features include contracts for examination and approval, the contract comes into force, the contract filing, contract changes, contract settlement and statistical analysis, etc. Module has the scalability and flexibility, easy to support for new areas of contract information.

(3) The Rights management module having management module. To different users according to their work done, assigned to the corresponding group, group is a collection of permissions, different groups have different permissions. First is planning user groups, will be assigned to the corresponding operator in the group, assign permissions for each group, namely menu items available and unavailable. When logging in first to determine the user's group, will set the permissions assigned to users, will not be able to operate the function of automatic block, so as to ensure the confidentiality, integrity and accuracy of data. 
(4) The Inventory accounting modules. Inventory is refers to the enterprise in the process of production and operation for sales or use and reserve all kinds of assets. In enterprise operation process, it is always in constant purchase, consumption, or sales of inventory, must carry on the inventory accounting of each accounting period. Inventory accounting is the enterprise accounting system is an important content of the right to calculate the cost of inventory purchased, reflect and supervise transceiver, brought back and keep inventory, promote enterprises to improve the using effect of money.

(5) The Salary management module. According to the national labor laws and policies, the release of the salary to the worker conducts planning, organizing, coordinating, guiding and supervising. Includes worker individual labor remunerations and according to the provisions of the state of allowances and subsidies and etc. The module is available for financial personnel of personnel and wages increase, delete, modify, and query, salary should pay the amount of items such as calculated by the system automatically, and at the same time can also be a multi-angle query in case of personnel and salary management.

(6) The Accounts payable module. Accounts payable is one of the types of accounting subject, is refers to the enterprises to purchase materials, supply of goods or accept services and other business should be paid to supplier's account. Accounts payable is due to the goods in the purchase and marketing activities of buyers and sellers do not agree with the payment on time and in debt. The other accounts payable of the enterprise, such as compensation payable, to cope with the rent, deposit, do not belong to the accounting content of accounts payable.

(7) Accounts receivable module. Accounts receivable said enterprises in the process of sales are occupied by the purchase the unit. With invoice, unit cost and other receivable list of original documents as the basis, record sales and other business form of correspondence, handling of receivables, bad loans and transfer. Payment according to the customers at different levels of business accounting and management, provide two solutions, namely the system of accounting receivable customers and payment for accounting the customers in the general ledger system.

(8) Accounting processing module. In set up accounting course system, on the basis of input credentials as a starting point, after a series of processing, accounting, invoicing and reconciliation work, the output of all kinds of general ledger, journal, subsidiary ledger and relevant auxiliary account. Accounting treatment is the core of the computerized accounting system module, the seamless connection with other modules and business module, realize data sharing and other modules related to accounting data will ultimately accrue to the accounting processing module.

(9) Report management module. Set the format of the report and prepare the formula, the system automatically generate a file to save the generated data tables. Obtained from general ledger system or other business related to the accounting information, automatic preparation of all kinds of accounting statements, the audit report, summaries, generate various analysis diagram, and a predetermined format output statements. Main functions include document management, format, data processing, graphics generation, print and secondary development.

(10) Fixed assets module. Fixed assets are the means labor enterprise of, but also the production and operation of company's main assets. Use time more than 1 year and value reaches a certain standard of non-monetary assets, including the production and business operation activities or management activities related to the equipment, instruments and tools. Fixed assets accounting and management is an important part of enterprise financial accounting, include the following main functions: management of fixed assets CARDS, changes in the increase or decrease in fixed assets, depreciation and net, etc.

(11) Cost management module. Cost management is refers to the enterprise production and management in the process of cost accounting, cost analysis, cost decision and cost control, and a series of scientific management behavior. Cost management mode including standard cost management, target cost management, cost management and strategic cost management, etc. Main features include: cost forecast, cost decision, cost plan, cost control, cost accounting, cost analysis, cost reports and cost performance management, etc. 
(12) Financial analysis module, analysis module. Financial analysis is an important link in enterprise management activity, is the use of the information disclosure of financial statements, the special analysis method, analysis of enterprise in the past and present operating results, financial condition, cash flow and the changes of enterprise economic management activities. In the preceding item accounting on the basis of the financial statements generate, extraction of accounts data or related financial information for analysis. Main functions include analysis project definition, financial formula preparation, report access and query, etc.

\section{Safety Control Design}

Information security is to point to the integrity, availability, confidentiality and reliability. The essence of information security is to protect information systems or information in the network information resources from various types of threats, the interference and damage. Information security is no country, the government department, industry must be attached great importance to the problem, is a national security strategy that not allow to ignore. Information security is an important content of the accounting computerization. As the accounting computerization from accounting stage, to the stage of informatization, management transformation, the accounting information processing technology and enterprises management activities increasingly close union, the accounting data processing by simply to "deal with" into the "information" for the center of the pursuit of high quality and efficient. The emergence of the Internet and the increasing popularity, marked the accounting computerization the arrival of a new revolution. At the same time, the accounting computerization system security problem is increasingly outstanding.

The security of the computerized accounting refers to a computerized system to maintain the normal and stable operation, system data security and integrity. Computerization of accounting work has brought accounting work efficiency, but also brings difficult to avoid security problems. The security problems of the computerized accounting system, the main performance $[5,6]$ in the following four aspects: one is that the computer itself fault and error caused by the significant data loss or errors, the second is that the accounting computerization and the problems of computer network security flaws in itself, is three, accounting computerization makes practice favoritism of damage and the loss is bigger, four is, computer virus and hacker attacks severely impact the accounting computerization security.

Security control center to provide foundation support for the accounting computerization, responsible for receiving and processing observation and system information collection and transmission components. Through the analysis of the characteristics of the controlled system, the control tasks into subtasks are assigned to each component is completed, we can realize the function of task decomposition; Manages the system parts at the same time, responsible for setting the function of various components and parameters. Accounting computerization safety control is the core of security control center, is responsible for scheduling "security platform" and "safety control platform" joint work, safety control structure is shown in Fig. 2.

Security platform mainly four task $[7,8]:(1)$ to ensure the safety of operation, from the aspects of the software to ensure that the main measures include: shielding illegal data input; To check the input data, to prevent errors; The second input mode to the special important data; For the standardized code data using the drop-down list box to select input.(2) to ensure the safety of operation, it is strictly prohibited in the case of not shutdown directly off the power switch; System check each function after operation, no alarm prompt to operate; System is running in the process of retrieval footprint regularly, if found abnormal memory and virus, and so on and so forth immediately report to the police.(3) to ensure the safety of data, data input, processing, statistical or printing process, when hardware failures, power outages, crash, artificial misoperation, bugs, such as a virus or hacker happens, take corresponding safety strategy, ensure no damage to the database or data is not lost.(4) to ensure the safety of communication, network communication security is through a variety of computer, network, cryptography and information security technology, ensure that the communication network transmission, exchange and storage of information in the complete, true and confidential, and the transmission of information and content has the control. Assurance 
measures are mainly to prevent transmission may have been intercepted, eavesdropping and tampering and forgery blows.

Security monitoring platform mainly completed four tasks: (1) to monitor user operations, to allow after identification of legitimate users, according to the granted permissions of terminal system operation, and put an end to the legitimate user unauthorized and illegal operation of the user's illegal operation, record the operation of the legitimate user behavior and the illegal user to operation;(2) the monitoring program is running, the controlling terminal of the operating system and applications run, timely discover and compensate for the security flaw in terminal system, allow only authorized program execution, prevent computer viruses or other malicious program illegal execution;(3) to monitor file access, control user access to terminal system of file operation, only allow legitimate users authorized directory or file read and write, to prevent unauthorized access and legitimate users illegally used to modify files;(4) monitoring system of communication, communication control terminal system and the accounting computerization system, allowing only specified port terminal system and opening up, run a specified service, send to specify communication requests, to prevent illegal penetration attack, denial of service attacks and leaks. In and out of the system of data monitoring and filtering, put an end to accidentally leaked sensitive data.

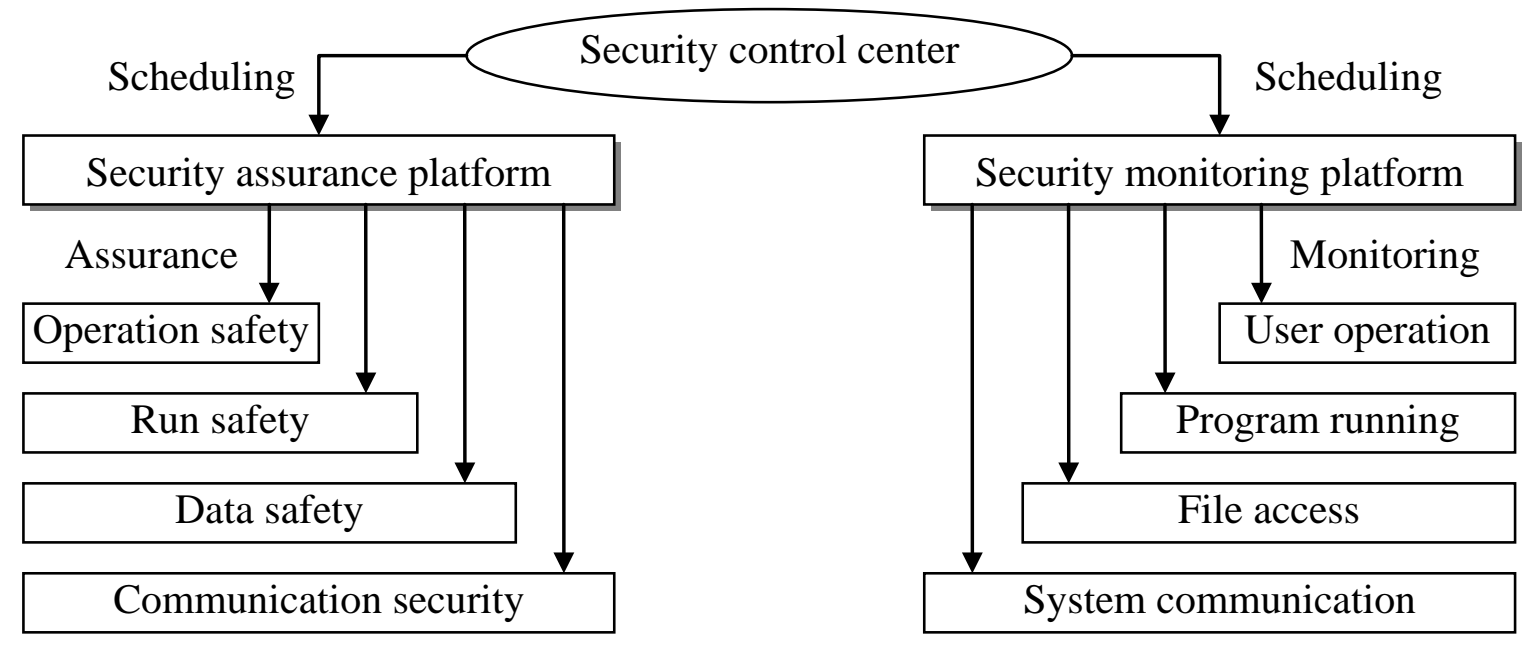

Fig. 2. Safety control structure on accounting computerization

\section{Conclusion}

The research achievements of this paper can solve the problem of key software development technology, which improves the quality of the accounting computerization software plays an important role and promote the accounting computerization software applications. Used in this paper, research and development of computerized accounting system has the following features: improve data accuracy, and reduce the errors caused by human factors, improve the quality of the accounting system. Improve the data processing speed, enhances the timeliness of accounting information; Digital data storage, and has a convenient storage, delete and modify a trace, etc. Internal control program, make originally in the manual accounting environment control system, the role of basic lost control; Centralized data processing, the original manual accounting work by the focus on software, data available to different users; Update billing processing, automatic data processing work, from the accounting voucher input output almost no longer requires human intervention to the financial statements.

\section{References}

[1] J. T. Ai, "Analysis on the security of computerized accounting system," Business Economy, vol. 32, no. 5, pp. 107-108, 2013. 
[2] Y. Zou, "Analysis of security of computerized accounting system," Journal of Harbin University of Commerce ( Natural Sciences Edition), vol. 28, no. 3, pp. 375-378, 2012.

[3] M. Ma, "The design and implementation of accounting computerization system in small and medium sized enterprises," Times Finance, vol. 36, no. 20, pp. 209-212, 2015.

[4] Z. Jia, "Software design method and application based on the ERP of the computerized accounting," Electronic Design Engineering, vol. 22, no. 17, pp. 26-58, 2014.

[5] Z. H. Zhao, "On the internal control of computerized accounting system," Internal Auditing in China, vol. 18, no. 1, pp. 29-32, 2014.

[6] Z. R. Li, "Design of contract management information system," Office Informatization, vol. 22, no. 26 pp. 51-53, 2016.

[7] S. S. Fan, "Problems and Countermeasures of accounting computerization in our country at present," Friends of Accounting, vol. 29, no. 32, pp. 48-50, 2012.

[8] X. L. Wang, "On the problems and Countermeasures of accounting computerization," Reform \& Openning, vol. 26, no. 12, pp. 80, 2011. 